\title{
INTERNATIONAL JOURNAL of

\section{BIO-PSYCHOSOCIAL FACTORS ASSOCIATED WITH THE USE OF SEXUAL ENHANCERS AMONG GHANAIAN MEN}

Dr. Samuel Atindanbila ${ }^{* 1}$, Mr. Asafo Seth Mawusi ${ }^{2}$, Mr. Alexander Attiogbe ${ }^{3}$, Mr. Edward Abasimi ${ }^{4}$, Mr. Philemon Amooba ${ }^{5}$

${ }^{* 1}$ Dept of Psychology,University of Ghana, Box LG 84, Legon

${ }^{2}$ Dept of Psychology,University of Ghana, Box LG 84, Legon

${ }^{3}$ School of Nursing,University of Ghana, Box LG 43, Legon

${ }^{4}$ School of Medicine \& Health Sciences, University for Development Studies, Tamale.

${ }^{5}$ Dept of Nursing, College of Health Sciences, KNUST, Kumasi.

*Correspondence Author: atindanbila@gmail.com

\begin{abstract}
:
This study explores the biopsychosocial factors that affect the decision of Ghanaian men to use sexual enhancers/aphrodisiacs. The study was qualitative in nature and made use of thematic content analysis as its main tool of analysis. Two focus groups involving ten (10) participants were used in the study. Participant age ranges was between $25-59$ years. Findings indicated that the decision to use an aphrodisiac involve a complexity of interactions between social, psychological and biological factors. The main social findings were that a man's sexual ability to perform sex is indicative of status and prestige in society. The psychological reason for the use of aphrodisiacs was to punish women. The biological reasons were to use sexual enhancers as tools to prove masculinity and as a function of age and absence of disease. The study also gave the easy availability of sexual enhancers in Ghana, as one of the reasons. Recommendations centred on education on the effects of sexual enhancers and their availability on the market be controlled.
\end{abstract}

Keywords:

Sexual enhancers, biopsychosocial factors, masculinity, prestige in society, Ghanaian men.

\section{INTRODUCTION}

Aphrodisiacs are substances which enhance sexual performance or aid in the proper functioning of the male and female sex organs (Sandroni, 2001; Shamloul, 2010). The quest for a true aphrodisiac - potion, pill or food guaranteed to enhance sexual experience, is as old as the human race itself (Sandroni, 2001).

Aphrodisiacs can be classified according to their effects when consumed or administered. Aphrodisiacs can have psychological effects, thereby increasing sexual desire and pleasure through hallucinogenic properties or other mood stimulating properties. Aphrodisiacs can also act physiologically, enhancing erection through hormonal changes, increased blood flow, and smooth muscle-relaxing properties (Sandroni, 2001). 


\section{INTERNATIONAL JOURNAL of RESEARCH -GRANTHAALAYAH

Sexual enhancer advertisements and other popular cultural depictions therefore participate in putting the spotlight on the performing penis as integral to masculinity. Sexual enhancers thus becomes a pill not only to repair, but also to enhance or improve, both erectile functioning and masculinity (Loe, 2004). Sex, does not occur merely between the individual partners directly involved, instead sex occurs within a broader social and cultural context, with implications for prestige, status, and reputation (Buss, 2003). In summary, aphrodisiacs have now become a means to enhancing a person's self-image.

In Ghana, anecdotal evidence seems to suggest that, both natural (mainly herbal) and chemical aphrodisiacs are used by men of all ages and status. The use of alcohol as an enhancer is exemplified in advertisements of alcoholic beverages and herbal concoctions with catchy names such as 'kebasho,AgyaAppiah bitters, waist and power, abrantie manpower bitters etc.'. It is helpful to note that, most of the herbal aphrodisiacs are prepared in a solution of concentrated alcohol (spirit).

Information from the Food and Drugs board Ghana, (FDB, 2011), shows that the total amount of drugs posing as aphrodisiacs that have not received governmental approval is worth over two million dollars. This seems to suggest a market and availability for these products in the country.Clomipramine (Anafranil) an anti-depressant has a side effect of inhibiting ejaculatory or orgasmic functions and as a result leads to prolong sexual intercourse (Impotence Association, 1999). This drug seems to be abused by most men due to its ability to inhibit ejaculation. The question that comes to mind is, why will men go to so such extents to abuse drugs, regardless of health complications just to enhance sexual performance? Thus the focus of this study is to investigate, the psychosocial determinants of the usage of sexual enhancers.

\section{OBJECTIVES OF THE STUDY}

1. To find why men use aphrodisiacs/ sexual enhancers

2. To examine the influence of cultural beliefs and practices on the use of aphrodisiacs/sexual enhancers among men in Ghana

3. To investigate the psychological reasons for the use of sexual enhancers

\section{SIGNIFICANCE OF THE STUDY}

The study will enormously contribute toward the sex literature by extending our understanding of the dynamics of men's decisions to use aphrodisiacs. The study will direct attention to the huge gap left unattended in the available literatures on the phenomenon of aphrodisiac use as it seeks to explore and offer suitable model for conceptualizing the reasons for which men use aphrodisiacs. The study will also inform policy makers in their decisions made towards the regulation of these aphrodisiacs in the country.

\section{METHODOLOGY}




\section{INTERNATIONAL JOURNAL of RESEARCH -GRANTHAALAYAH

\section{RESEARCH SETTING}

The data for this study was collected among men in the University of Ghana. The justification for this particular sample is based on the fact that, the university is made up of people from different walks of life and a such a sample selected from this population will reflect to a greater extent the accurate views of Ghanaian men regarding the use of sexual enhancers.

\section{PARTICIPANTS/ SAMPLE}

Purposive sampling was used in the selection of participants. This sampling technique was considered appropriate because the study specifically targeted people using aphrodisiacs and people who were willing to be a part of the study. The inclusion criteria for this research were that a participant was an active aphrodisiac user. An advert was put on the notice boards concerning the study and interested participants were required to call to confirm participation.

In all, 10 men were sampled for this study. The participants fell between the ages of $25-59$ years.

\section{RESEARCH DESIGN}

The research design was qualitative in nature. This design was chosen because the aim of the study was to explore and gain sufficient knowledge on the psychosocial reasons why men use sexual enhancers/aphrodisiacs.

\section{MATERIALS}

A tape recorder was used to record the group interaction to allow for accurate analysis of the data as well as a constructed semi-structured discussion guide containing the types of questions to be asked. Besides, a notebook was carried along to take notes from the observations and informal conversations to add to the recorded discussions (Emerson, Fretz\& Shaw, 1995).

\section{PROCEDURE / DATA COLLECTION}

There were two phases of the discussions. The first phase was the focus group interaction with the participants, and the second phase of the discussion involved getting back to some of the participants to confirm whether the findings reflected their views recorded in the group discussion.

\section{FINDINGS}

\section{INTRODUCTION}

The main objective for conducting a qualitative study was for the researcher to explore the extent to which Ghanaian men understand aphrodisiac and the factors that cushion its usage.

SOCIAL FACTORS 


\section{INTERNATIONAL JOURNAL of RESEARCH -GRANTHAALAYAH \\ A knowledge Repository}

Science

The social factors in this study referred to cultural and societal expectations of a man in the Ghanaian context. For instance, you see with respect to masculinity, basically a man must be able to do three things, firstly put food on the table, secondly take care of his family and the most important one satisfy his wife in bed. Let me tell you the Ghanaian definition of a man starts in private, so that before you can be seen as a man what you do in private counts a lot. (Respondent 3 )

This participant explicitly indicates that the social construction of masculinity is based on three factors, with an overarching emphasis on sexual potency. His emphasis of sexual potency is crystallized in the manner he perceives masculinity as issuing from privacy; implying that a man's public endorsement is only a consequence of a perceived non-public performance (i.e., sexual performance).

Another participant validates this interpretation when in another dimension virility becomes connected to status. For instance:

...if you're not doing too well in bed and your wife is not complaining then be careful, somebody else is doing her...I mean in the Ghanaian context, wealth and children are the things that give you status so if you are impotent, you are ridiculed so yes these enhancers are a means to preserving our ego.(Respondent 4).

To explore this main theme further a detail examination is presented below in three main subthemes: To portray or preserve masculinity, The influence of friends and family and The influence of the media.

\section{TO PORTRAY OR PRESERVE MASCULINITY}

The account of men from the focus group discussions proved that men used aphrodisiacs because they are concerned about their sense of being a man. This theme explored one of the reasons why they would use sexual enhancers; it also examined the definitions men attached to themselves as well as perception of society with respect to sexual performance. For instance,

I think mmm, it helps to be able to prove yourself to a lady, mmm...to prove to your girl that yeah you are capable of being a man......you really want to prove yourself that yeah you are a man yeah...i think the satisfaction of a lady counts a lot here, mmm most at times, we use this just to satisfy the lady, to prove that yeah am capable of being good in bed and all those things. (Respondent $B$ )

This participant finds that inability to socially validate his masculinity in the context of sexual intercourse is demeaning.

.......ladies of today want to...you know......mmm they can give you names or make fun of you if you don't perform sexually....yeah sometimes I think I also want to prove myself as a strong man...I would want to prove that I am a man in most of the instances in which I have had to use a sexual enhancer than enjoying it personally. (Respondent D)

This participant, clearly states that, inability to prove manly, is associated with ridicule from women. Another participant, endorses this view when he said, 


\section{INTERNATIONAL JOURNAL of RESEARCH -GRANTHAALAYAH \\ A knowledge Repository}

Science

...show we are men. As a man, you must be able to satisfy your woman and let her know that yes! You are a man. ... if you don't perform in bed, women laugh at you and they don't respect you...look even if you buy your wife a plane and build her a castle and you are not able to do the do in bed, she will not respect you. (Respondent 1)

I think that as a man you must be diverse and every woman needs the satisfaction so definitely in your quest to make them all feel good, you need to take a "lawyer"...you may disgrace yourself so the sexual enhancer will actually help you maintain your reputation. (Respondent $C$ )

This respondent clearly emphasises the point that in his quest to satisfy every woman in his life, the need of an aphrodisiac is necessary.

In portraying or preserving masculinity, accounts from respondents used in this study, indicated some respondents who would hide their use of aphrodisiacs from their women therefore creating a false impression. For instance,

Ladies are very cunning, like as I said, they get to know you are using aphrodisiac, it's going to be the end for you. It's going to be like, while others are like I can go one hour naturally and all those things, you are hiding underground to like prove to... you are a man enough, what happens tomorrow if you didn't get the drug... they know the truth of it Ah ah! They look at you some way. (Respondent B)

The participant above, explains the point that, it is demeaning to let a woman know you use sexual enhancers as a man.

...Actually, we actually try to hide that from them, you don't want them to know that it is not you. Yes so you hide and then you use it and then you let them think that, that is all you natural, everything is you...she will not be impressed any longer, she would feel o! so it takes a drug for you to perform, naturally, you can't actually perform. So then you are not a man enough. (Respondent A)

... why would I let her see it. I mean we are trying to impress our women by making them know we are stallions in bed, if she sees it, the respect for you will just drop. (Respondent 3)

Ah! I see no reason why your lady should know you use an enhancer. It's a straight insult on a man's dignity. They believe that you are a tiger in bed, so other men don't look appealing if they find out, it defeats the whole purpose. (Respondent 2)

The above extracts, give insights into the matter of men not wanting women to know they use aphrodisiacs. They move further to show that, a woman in the knowing will no longer hold you in high esteem. This portrays that men want to create false impression in their ego preservation.

(guys whispering)... you know what, whenever we go to the lavatory, everybody know what we are doing there, but my question to you that, does that fact....mmm will that make you able to come and shit in public? (Heads shaking), that's kind of how the feeling is (Handshakes and laughter). (Respondent 5)

\section{THE INFLUENCE OF FRIENDS AND FAMILY}




\section{INTERNATIONAL JOURNAL of RESEARCH -GRANTHAALAYAH \\ A knowledge Repository}

Science

The sub-theme influence of friends and family in this context refers to the role that family and friends play in a man's decision to use aphrodisiacs. For instance,

Yes my friends, at times, when you go and do it with a girl and you don't last, you come and tell your friends and they laugh at you and tell you oh! There is a way to make it better, you know, if you use an aphrodisiac, you will go and the girl will be impressed and all that. So actually it is friends and siblings that influenced me to use it...when friends and siblings meet, they do talk about sex and they do talk about their experiences, so you see at times, you have some of your friends or brothers complaining... (Respondent A)

I have had a girlfriend who understood some of these things. She was really supportive; she would even prescribe some of these aphrodisiacs at times to me. Because at the end of the day, we are all trying to achieve the same thing, gratify ourselves(gives a proverb in the local language literally meaning we are all drunk to the same level) so that is how I would say it. (Respondent C)

Okay... (Thinking)... i think it was my brother. You know guys talk about sex a lot, I didn't complain of any weakness he just came up to tell me of a new discovery that was working wonders. Am grateful he did (Men laughing) (Respondent 4)

... it was my girlfriend. You see when I was younger, I had a girl who liked sex a lot and she...I think she got me some that could make me stay on it for long. Correct mixture "paaa"(giggles) (Respondent 2)

Very sure it was friends. I remember during my high school days I used to be very naughty and we used to visit town. Now these girls gave us sex for money and it was on a one round release basis so just to stay longer before release we took different kinds of what have yous. So I guess it's still the friends' influence. (Guys clapping and laughing). (Respondent 3)

The extracts above goes to emphasize that friends and family not forgetting significant others in society can actually play a role in altering a man's decision in using an aphrodisiac. It goes further to elaborate the fact that men openly discuss their sex experiences with fellow men and thus setting the stage for aphrodisiac use discussions.

\section{THE INFLUENCE OF THE MEDIA}

The sub theme influence of the media, examines the role the media plays in a man's decision to use aphrodisiacs. For instance,

Basically through radio adverts, I hear the name and then go to the shop and get some. (Respondent C)

The internet, you always receive mails about some enhancer either making it bigger, longer, and firmer and those things. Even when opening a webpage, you will just get a pop up about some drug for sex. These adverts, makes a man curious so I think err...yes. (Respondent B) 


\section{INTERNATIONAL JOURNAL of RESEARCH -GRANTHAALAYAH \\ A knowledge Repository}

Science

The above participant from his statement, explains the fact that the media influence is so severe that, you don't have to find it (aphrodisiac) but it will rather find you.

The extent of media influence is fully realized when this participant saids, I would say.....mmm advertisements got me curious, and then friends confirmed their potency and gave even more insight than the adverts did. So I will say both adverts and friends. I mean the number of TV adverts about some drink that can, you know make a man a lion are endless, as for the radio ones, (laughing) hmmm. (Guys laughing) (Respondent 1)

\section{PSYCHOLOGICAL FACTORS}

The psychological factors refer to issues of personal perception as well as appraisal. These factors are more individualistic in nature. Five sub-themes we identified here, they were, phrodisiac use as a punishment tool, aphrodisiac use for sexual satisfaction and excitement, aphrodisiac use as a means to maintaining multiple sexual partners, aphrodisiac use as a result of positive feedback and finally perceptions of aphrodisiacs.

\section{APHRODISIAC USE AS A TOOL FOR PUNISHMENT}

The accounts of men revealed that, sometimes they would employ the use of aphrodisiacs as a means of punishing women for particular behaviours. For instance,

...for example, taking the instance of you trying to get hold of a lady for about three years and the lady has proven stubborn for some time, and you finally lay your hands on her, I think the first day you would want to go the extra mile to at least, sort of teach her a lesson you know, to pay her you know for err, delay or whatever. (Respondent C)

...Let's take these scenarios imagine a girl you have been wanting for a long time who has really stretched, you and when I say stretch I mean she has really spent your money, you have made so many sacrifices and you know very well you can't get anything better out of that relationship, when you finally get her, it won't be about love or feelings but rather, something like teaching a lesson. (Respondent3)

You see women of today make boasts, they go like, "you can't handle me" and such sayings kind of insults our ego so when you get hold of such a lady, it's now beyond pleasure but rather a lesson for underrating you. (Guys laughing and nodding in approval) (Respondent5)

I would use it sometimes like my brother C said, you know to punish a girl who has been stubborn, you have been perusing for a long while and then you finally get her, you know you want to kind of, sort of teach her a lesson. So I would use it to punish her. (Respondent D)

... a guy who works in a bank and had an affair with one of the ladies there. He messed up and got the nickname quick authentication, the ladies used to call him that and he knew it was because of what happened that day. He complained and you know as guys we made some recommendation 


\section{INTERNATIONAL JOURNAL of RESEARCH -GRANTHAALAYAH \\ A knowledge Repository}

Science

(laughing), he managed to convince this lady for a rematch and he did damage that day, according to him, the lady was crying and shouting for help and afterwards she was bruised and he felt very good about that. So in that instance, he was actually punishing the girl for making fun of him so yes I think as a means of punishment I also agree. (Respondent 1)

From the above extracts, some participants $(n=5)$ explained that they would employ the services of aphrodisiacs as a means of punishing women. In their extracts, it is clear that their intention to punish is the force behind aphrodisiac use.

\section{APHRODISIAC USE FOR SEXUAL SATISFACTION AND EXCITEMENT}

The accounts of men from the focus group discussion also revealed that, the use of aphrodisiacs was also for the purposes of sexual satisfaction as well as excitement. For instance,

Well I think that sometime we take these enhancers to make us enjoy the sexual process more because the longer you stay on it, the more you enjoy it. Besides when you are on it and she is enjoying it, the sound she makes alone makes you the guy enjoy it more (guys laughing) oh yes!... Once I tried an enhancer called horny goat weed, that day I enjoyed the sex more than any other day. And on subsequent occasions too I enjoyed it so much she told me I kept saying silly things (Guys laughing and asking for the name of the enhancer). (Respondent 4)

In fact on the enjoyment issue, I think that using the enhancer is actually a way of making the woman enjoy more because like 2 said, most of these enhancers you apply on the penis, actually kill the feelings so that you are just doing it not for enjoyment but to please her. Let's get real it's the climax that's the sweetest part of the whole thing and we could have the enjoyment in a minute or a few minutes but why do we go through all this to stay long, honestly I don't think it's for ourselves but rather the ladies (guys nodding in agreement). (Respondent 6)

I think err, the satisfaction or the elation aspect of it comes when after maybe an hour or two you still see the penis standing (guys laughing) but the lady might have been exhausted by then ... then you then tell yourself have been able to do it... (Respondent $C$ )

The above extracts although contradictory on who enjoys the sex more, still confirms the fact that aphrodisiacs are used as a means to sexual satisfaction and excitement.

\section{APHRODISIAC USE AS A MEANS OF MAINTAINING MULTIPLE SEXUAL PARTNERS}

The accounts of men in this study also revealed the fact that men used these aphrodisiacs, as a way of maintaining multiple sexual partners. For instance,

Let me say that err, you must always have a reserve player for a match just in case. However, most of the time, you enjoy the substitute more than the main player which is your wife and as a result, you need help to make your wife/girl feel you are not in any way seeing someone else so yes that is also a reason for aphrodisiac use. (Respondent A) 


\section{INTERNATIONAL JOURNAL of RESEARCH -GRANTHAALAYAH \\ A knowledge Repository}

Science

... as time goes on, the performance dips and women read this as an indication that you are seeing someone else so you are sharing your power in bed with some other lady. So just to clear that notion, you need these aphrodisiacs to get that power to drive your wife for her to see she is the only one. (Respondent 2)

... you know we are no saints after all variety is the spice of life so yes we may have some other women in our lives apart from the real madams. This is the case when you visit madam A she wants sex and you have to give it to her right, right after that, madam B also calls you would not want to but you have to so yes these enhancers must come. (Respondent 6)

Madam proper also wants her fill, without these aphrodisiacs, she will definitely see that you are cheating so yes! It's a means to maintaining other relationships apart from the original one. (Respondent 5)

The above extracts go accentuate the point that, in trying to prevent spouses of finding out about multiple relationships of other women with their men, they employ aphrodisiac as a camouflage. These opinions although subjective, emphasizes that some men believe that when a man is capable of satisfactory sexual behaviour to his wife, it is almost impossible to know whether he is cheating.

\section{APHRODISIAC USE AS A RESULT OF POSITIVE FEEDBACK}

The accounts of the study also uncovered positive feedback from aphrodisiac use as influencing men's decisions to use them. For example,

... because using it yourself after a game, the way the lady may say thank you is just some way, like ho! I am a hero... (Respondent B)

...then later when they try it out, you want feedback so you go like, how was it? And you know who ever I have recommended to, they've really had results. (Respondent A)

(Laughing)... I think that satisfaction is an understatement. I mean aside feeling good about yourself, the praises you get from the woman is another thing to be proud of so that you are driving and out of the blue you just laugh because you remember a comment like man you're a dragon (guys nodding and laughing uncontrollably) (Respondent 1)

...You don't just feel good you know, you walk around shoulders high. You all know what it feels like when after the act you get the woman say things like thank you, you're the best.......(Guys laughing) and stuff like that.(Respondent 3)

...my other friends to which I have made recommendations they have given me some positive feedback and that alone is also satisfaction. (Respondent 4)

The above extracts, talk about the fact that men use aphrodisiacs as a result of the positive effect directly experienced or the narrated results from other men 


\section{INTERNATIONAL JOURNAL of RESEARCH -GRANTHAALAYAH \\ A knowledge Repository}

Science

The account of men from this study, describes their definitions of aphrodisiacs or ideally what an aphrodisiac should be able to do. For instance,

I think it prolongs sexual desire and hours and increases the energy levels (Respondent B)

... aside prolonging, it also actually promotes erections itself by adding to the power in the penis that is hardening it better than ordinarily...I think to everything there is a primitive way of doing it or let me say the manual way and the modern way with repose to technology,...I think aphrodisiacs are one aspect of technology that the Whiteman has been able to invent (Respondent C)

......any substance that can increase the size of the penis (Respondent 6)

You see in old age, you erections are not so hard, so anything that can keep your penis firm even into old age ...I am of the view that with respect to strides in technology, this has been an area that is flourishing dramatically (Respondent 5)

I think that, err, apart from the fact that an aphrodisiac can give a man stronger erections and longer abilities to stay on it, I believe it moves a step further by also arousing or putting you in the mood. (Respondent 1)

...what makes an old man perform like a young man...what makes an impotent man potent... aphrodisiacs are relationship magnets or better to say they mend broken relationships. (Respondent 3)

The above extracts, actually tell you for what purposes a man uses an aphrodisiac. Their perception of the aphrodisiac or their personal definitions of it or in other words what they want the aphrodisiac to do for them is of major concern in their decision to use a sexual enhancer.

\section{BIOLOGICAL FACTORS}

The biological factors in this context, examined factors that cannot be controlled directly in a man's decision to use sexual enhancers. Three (3) sub-themes were realised here. They were, issue of aging and disease, the issue of habituation and finally the issues of phlegm and fatigue.

\section{ISSUE OF DISEASE AND AGING}

This sub-theme, explored the effects of age and disease on sexual performance. For instance,

I think err, age, the factors of age and disease, I think, they really, you know play or, they really factor in our decisions to rely on aphrodisiacs. I have had an experience, I know of a certain man way back in the Western region, but he is a bit aged, err, he went in for a very young lady and then, almost every day after you know, sweeping, you know, you will find packs of some of these aphrodisiacs so there is the possibility that, he's been using it almost every night and the man I think he is grown so his age is now you know playing an important role in his decision to rely on these aphrodisiacs. (Respondent $C$ ) 


\section{INTERNATIONAL JOURNAL of RESEARCH -GRANTHAALAYAH \\ A knowledge Repository}

Science

I think I agree that age and mmm disease play a role in our decision to use some of these drugs because, for instance, a disease like Kooko which is also known as piles, can cause a guy not to you know, not perform very well sexually. ...I think age could be a cause because, if normally, if you are younger, you are more able to perform better than ... (Respondent D)

I think that another important reason why men use these enhancers is as a result of age. (Men nodding in agreement). You see as you age, you lose the energy of youth and even sometimes the desire but thankfully, these enhancers have come in to solve such problems for us men. I mean so many men in the world take Viagra because their erections are failing, so age is another important factor. (Respondent 1)

...with aging come illness etc. and these in themselves cause sexual weakness. For example as we age the number of medications we take to stay healthy increase and all these have side effects I think that some of the side effects may lead to sexual weakness... I mean we all know the saying old age is a disease. (Respondent 4)

... you see although we are aging we still have feelings for the thing and not that we are doing it with old people too. Men today no matter how old are marrying girls far younger than they are, so yes as our performance decreases. (Respondent 3)

From the above extracts some men $(n=5)$ were in agreement with the fact that with age come disease and as such a decrease in sexual performance. In their accounts, age and disease cannot be considered in isolation and as such the decision to use an enhancer is directly tied to aging.

\section{$\underline{\text { THE ISSUE OF HABITUATION }}$}

This sub-theme examined issue with respect to being used to sex or the "phenomenon of overdoing". For instance,

...I think that frequent sexual intercourse could cause sexual weakness. Mmm taking myself as an example, I think when I was much younger, when I had, back then when I was like 18,19,20 when I was frequently having sex, I think that I could go you know longer periods than I do now. (Respondent D)

...I think too much sex, weakens a man or a guy as my brothers put it, so I think that as age catches up on you, you know there is the tendency for you to rely on aphrodisiacs as helps to maintain the standards that you've set you know decades ago. (Respondent $C$ )

I think that excessive sexual activity also decreases a man's ability in bed. It's just like a car, the more you use it, the more wear and tear sets in. for example when I was younger I think I had too much sex so at about age 26 I was already weak. (Respondent 2) 


\title{
INTERNATIONAL JOURNAL of RESEARCH -GRANTHAALAYAH \\ A knowledge Repository
}

Science

The above extracts, emphasizes the phenomenon of "wear and tear" the view was that, the more you engage in sexual intercourse, you are weakened by the act itself and therefore the decision to use sexual enhancers by some men is influenced by this.

\section{THE ISSUE OF PHLEGM AND FATIGUE}

This sub-theme was realized from the accounts of men from the focus group discussion which explained that phlegm and fatigue are impediments to maximum sexual performance. For instance, ...when you use it, it purges you so you "run" very frequently so when it's time for the game, I mean, it kinds of removes all the phlegm from your waist. It really helps you to perform...I think my problem also has to do with phlegms. I know that without the phlegms I always do very well... (Respondent D)

I currently am focused on the phlegms in my waist, if am able to get them out of the way, I think they are the current impediments...I think you know it all results from the food we eat. You know, too much starch, they get embedded in our bodies, I think some of the end products you know, they turn out to be phlegms and they get deposited in our waists ok (Respondent $C$ )

...err let me quickly say that, the phlegm issue must not be joked with at all. My brothers it can disgrace you. (Men laughing and shaking hands) (Respondent 6)

AdomKooko bitters kinds of purges your system from phlegms...you see, phlegms that build up in your waist, reduces your power... (Respondent 2)

Mine is a little advice, when you are tired, do not venture a sex, you will seriously lose the match. (Respondent 4)

... if you are too tired, sometimes you will not even get up, but you take your Viagra and somebody is screaming for help (Guys laughing)... at times, you really have to impress and mmm maybe you are too tired... you know so many barriers. (Respondent A)

The extracts above, highlight the fact that, waste in the body in this case phlegm actually impedes sexual performance and that with purging come the old ability to perform effectively in bed. In this instance, a man's definition will be related to substances that are capable of purging the body. Fatigue which is also seen as an impediment to maximum sexual performance can be addressed using sexual enhancers. In this instance a tired person's definition of an aphrodisiac will be a substance that can arouse and also provide energy for sexual intercourse.

\section{DISCUSSION AND CONCLUSION}

\author{
INTRODUCTION
}




\section{INTERNATIONAL JOURNAL of RESEARCH -GRANTHAALAYAH \\ A knowledge Repository}

Science

The present study explored the biopsychosocial reasons that account for men using sexual enhancers. Thematic content analysis was used to analyze the qualitative interviews to produce themes that were significant to the aphrodisiac use phenomenon which are discussed below:

\section{WHAT ARE THE SOCIAL OR CULTURAL REASONS WHY MEN USE SEXUAL ENHANCERS?}

Social factors looked at influences from the social environment or external sources, that affected a man's decision to use aphrodisiacs or sexual enhancers. The social factors also examined issues with relation to societal expectations and pressures from friends, family and significant others. The analysis of data revealed that, friends and family play a very vital role in a man's decision to use aphrodisiacs, this finding is consistent with the findings of Rubin (2004). From the accounts of men, talk of sex is a common practice among Ghanaian men and performance is a thing to brag about. As a result, in such discussions, there is an influence effect that actually propels men to engage in aphrodisiac use. The media also forms part of the social world and a vital agent of information dissemination, the study realised also that the media played another vital role in a man's decision to use sexual enhancers. This finding is also consistent with the work of Rubin, (2004). For instance, in Ghana presently, the number of radio and television adverts promoting a pill or a drink with aphrodisiac properties are countless, a typically example is the advert on angel ultimate man capsules advert on radio and storm drink which is shown on television. The findings also realised that in the quest to preserve or prove masculinity, men of all calibres engage the services of aphrodisiacs. This finding was consistent with the findings of (Baglia, 2005a, 2006b; Gannon, Glover \& Abel 2004). From the study, it was also inferred that sexual performance is tied to prestige, status and enhancement of reputation. This finding is consistent with the work of Buss, (2003).

Analysis of data revealed that men used aphrodisiac without wanting their spouses to be aware of it, thereby creating a false impression of manhood. Analysis of the data also showed that, the definitions of a man in the Ghanaian context started in private; it also brought insights to the fact that although wealth is a requirement for social respect, children were the most important facet of a man's respect in society and as such an impotent man was ridiculed by all. This finding is also consistent with the findings of Singh et al, (2010) when he clarifies that impotence affects the quality of life of a man. In addition to the above, the non-performing man, had results of his wife or woman seeing other men. The inability to perform in bed, also brought about serious issues of disrespect on the part of a woman. For example, the accounts of men showed consequences such as wives not cooking or washing their husbands' things as well as statements such as "he is not a man" and teasing from the ladies.

With respect to masculinity, it is helpful to examine some of the labels that men accord themselves; for example, men used statements such as, "stallion", "Horse" "Dragon"etc. these are all animals of fierce repute and for men to refer to themselves as these further shows their definition of themselves. 


\section{INTERNATIONAL JOURNAL of RESEARCH -GRANTHAALAYAH

In light of all the above, the Ghananian man not wanting to be disrespected by women, engage the services of aphrodisiacs. Men in this study were of the view that, when a man does not perform sexually it leads to disrespect from their women as well as cheating on the woman's part. This seems to suggest that, if you do not satisfy your woman sufficiently and she cheats on you, you are actually to blame for her actions and although society may frown on a cheating woman, it may also justify the action based on the fact that his man wasn't a man enough.

\section{WHAT ARE THE PSYCHOLOGICAL REASONS WHY MEN USE SEXUAL ENHANCERS/APHRODISIACS?}

Psychological factors, explored issues of personal definitions of aphrodisiacs as well as issues of intent, perception, appraisal and reinforcement.

The subjective definitions of aphrodisiacs given by men depend directly on what a man desire an aphrodisiac to do for him. For example, a man with a small penis seeking enlargement will define an aphrodisiac based on its ability to enlarge the penis, also a man with virility issues will define an aphrodisiac based on its ability to make a man virile. Also depending on what a man wants he may choose to use different aphrodisiacs for different purposes. This illustrates the perception component of aphrodisiacs. From this study it was uncovered that men viewed these aphrodisiacs as blessing not only to enhance, but to save the failing masculinity crisis in men. This point seems to be consistent with the work of Connell, (1995). Also, aphrodisiacs were perceived as advancement in technology which was also confirmed by Fox and Ward, (2008).

Analysis of data revealed that, men used aphrodisiac as a way of maintain multiple sexual partners. In their opinion, performing adequately eliminates all suspicions in the eyes of your woman. This finding is consistent with the work of Buss and Shackelford, (1997) which explained that men used enhancers as a way of mate guarding. From this study, it was also uncovered that, a reduction in sexual performance leads women to the belief that a man is sharing his sexual abilities with other women. Mate guarding is a vital reason why men have sex. (Schmit, 2004; Schmit\& Buss, 2001)

Analysis of data also revealed that men used sexual enhancers as a means of punishing women. The findings of the study indicated that, when a woman proves very stubborn, once a man gets hold of her, the feeling moves beyond pleasure and takes on a malicious intent of punishment. This finding is consistent with the work of Greiling and Buss, (2000). From the data, it was realized that, in recent times it takes considerable time and resources to convince a woman to have sex and as the process of convincing prolongs, so does the resources so that the longer it gets the more a man feels that a woman wants to take advantage of him. In that respect when a woman gives in, a man wants to sort of break even by enhancing his performance so that all the expenses are catered for kind of.

Analysis of data also uncovered the fact that, men use these aphrodisiac in a quest to increase sexual satisfaction as well as excitement in accordance with the findings of Leigh, (1989) and Hill and Preston, (1996). From the data men gave varying opinion concerning sexual excitement 


\section{INTERNATIONAL JOURNAL of RESEARCH -GRANTHAALAYAH

however, they all seemed to agree that the use of these sexual enhancers, actually gave more of the excitement and satisfaction to women than to men.

The psychological component of aphrodisiac use also revealed that, the use of aphrodisiacs was influenced by the feedback that these aphrodisiacs gave in themselves or the feedback that men observed from other men using it. This particular assertion is similar to the principle reinforcement (Eagly\&Chaiken, 1993). The observed positive effects or the direct positive effects, encourages men in their use of these aphrodisiacs. For example, the study uncovered the fact that men recommend sexual enhancers among one another and the thrill is in coming back to tell them whether the aphrodisiac was potent and by so enhancing the reputation of the prescriber.

In summary, the major findings of the study revealed that men's private use of aphrodisiacs creates a false impression of their sexual prowess determining their manhood. The findings brought out the view that, it is not only wealth that enables a Ghanaian man to earn social respect, children were a major determinant of that respect because it is also an indication of the fact that the man is not impotent; as such persons are ridiculed in the society. Psychological factors such as perceptions and appraisals impact men's decisions to use aphorodisiacs. Though the study set out to study only the psychosocial factors, a major discovery made was that biological factors also play a role in a man's decision to use aphrodisiacs. These were found in the effects of habituation, the influence of age and disease. It was also discovered that, men adopt sexual enhancers because of phlegm and fatigue. The discussion throws light on the fact the perceptions and appraisals made by these men in their decision to use aphrodisiacs relate to factors that are associated with their own processing of events and although subjective, a true reflection of which condition would elicit the use of aphrodisiacs.

WHAT ARE THE BIOLOGICAL FACTORS THAT WOULD MAKE MEN USE SEXUAL ENHANCERS?

The study set out to investigate the social and psychological reasons why men use sexual enhancers. However, another discovery was made explaining that, biological factors also play a role in a man's decision to use aphrodisiacs. Among the biological reasons where the habituation effect, the influence of age and disease and the issue of phlegm and habituation.

Consistent with the work of Delamenter and Moorman (2007) the analysis of data, brought to light the fact excessive sexual intercourse across the lifespan actually weakens a man physically. The basis for their argument was grounded in the fact that, just as a car wears down as a result of overuse, the human body was also likened as such. From the accounts of men, although some were still young, they observed that, their sexual abilities earlier were more appealing than it is now. Some also made the observation that when then stay away from sex for a while and then initiate it again, they realise that their performance has actually increased.

The findings of the study also gave ground to explore a phenomenon that has been under research for some time. The findings of this research exposed the fact that age and disease affected the 


\section{INTERNATIONAL JOURNAL of RESEARCH -GRANTHAALAYAH

sexual performance of a man. From the accounts of men, they explained that, age and disease cannot be considered in isolation, this is emphasized in a statement by one of the participants who says "age is a disease". A vital finding was the fact disease in the function of age. This finding is consistent with the work of Delamenter and Moorman, (2007)

A final factor under the biological reasons why men adopt sexual enhancers was the issue of phlegm and fatigue. In the accounts of men, phlegms were excessive starch deposits that are locked up in a man's waist as a result of lifestyle. They explained that, an excess of this actually prevents a man from satisfactory sexual performance. The belief that phlegm reduces sexual performance is further emphasized by adverts of herbal drugs and mixture for the sole purpose of purging the human system of these impediments. One other factor that was realised was the fact that, fatigue impedes on sexual performance.

\section{RECOMMENDATIONS AND IMPLICATIONS OF THE STUDY}

This study, has given evidence for the fact that, men in Ghana use aphrodisiacs and are not particularly keen on the type so far as it is able to enhance their sexual functions. The study has also shown that some men think of aphrodisiacs as a blessing and by extension are continuously going to use them because they are positively reinforced to do so. In the light of this evidence, it will be a great health concern if regulations are not put in place to check the authenticity of these aphrodisiacs. It is recommended that, the Food and Drugs Board (FDA) regulate the flow of these drugs into the country. Sanction should also be raised against people or agencies that are responsible for the manufacture and sale of all aphrodisiac drugs that have not received FDA approval

The study also found out that, majority of the aphrodisiacs used by Ghanaian men are traditional or natural in nature. The Ghana Herbal Council in collaboration with the Centre of Scientific Research into Plant Medicine (CSRPM) must be given the mandate to regulate and certify all herbal productions that are considered worthy of being called an aphrodisiac. Considering some of the side effects of burning sensations and priapism, it is imperative that education be given by the Ghana Health Service (GHS) to men on the harm that these "petty" effects can have on them in the near future so that the use of these sexual enhancers can be controlled. It is also of great importance to vet or regulate the kind of advertisement in the media as a whole on these sexual enhancers. The findings of the research unveiled the fact that, some men have come to use aphrodisiacs because of the kind of information they acquired about it through the media.

The main findings of the study, indicated that, the decision to use sexual enhancers is based on the following factors; social, psychological and biological. The findings are very relevant to the field of psychology because there is lack of information on this aspect of sexual practice in Ghana. The findings of this study will go a long way to help the Ghana Health Service, clinical psychologists and counselors to be able to understand and plan strategies to help such clients and their spouses.

On a social basis, the findings of this study, implies that the sense of manhood and influence from family and friends play a significant role in men's use of sexual enhancers. This suggests that, 


\section{INTERNATIONAL JOURNAL of RESEARCH -GRANTHAALAYAH \\ A knowledge Repository}

Science

men's use of sexual enhancers is as a result of social expectations and pressures. These social expectations come from the influence of direct relatives and close associates which makes aphrodisiac use an inexorable part of a man's life. Another factor that throws more light on societal pressures has to do with advertisements. These advertisements are giving what society expects of a man with respect to sex and as such is influencing men in their use of sexual enhancers. Therefore, their uses should be controlled by media commission in Ghana.

\section{CONCLUSION}

The present study explored the biopsychosocial reasons that account for men using sexual enhancers among students and staff at University of Ghana. Thematic content analysis was used to analyze the qualitative interviews to produce themes that were significant to the aphrodisiac use. Two focus groups involving ten (10) participants were used in the study. Participant age ranges was between 25 - 59 years. Findings indicated that the main social findings were that a man's sexual ability to perform sex is indicative of status and prestige in society. The psychological reason for the use of aphrodisiacs was to punish women. The biological reasons were to use sexual enhancers as tools to prove masculinity and as a function of age and absence of disease. The study also gave the easy availability of sexual enhancers in Ghana, as one of the reasons. Recommendations centred on education on the effects of sexual enhancers and their availability on the market be controlled.

\section{REFERENCES}

1. Baglia, J. (2005) The viagra adventure: Masculinity, media and the performance of sexual a. health. New York: Peter Lang Publishing.

2. Baglia J. (2006). The viagra adventure: Masculinity, media, and the performance of a. sexual health. Journal of Sex \& Marital Therapy, 32, 425-431

3. Buss, D. M. (2003). The evolution of desire: Strategies of human mating (rev. ed.). New a. York: Basic Books

4. Buss, D. M., \& Shackelford, T. K. (1997). From vigilance to violence: Mate retention tactics

a. in married couples. Journal of Personality and Social Psychology, 72, 346-361

5. Connell, R. W. (1995) Masculinities .Berkeley and Los Angeles: University of California a. Press.

6. DeLamaterJ.,\& Moorman S.M (2007). Sexual behavior inlater life.Journal of Aging

a. Health; 19: 921-45.

7. Eagly, A. H., \& Chaiken, S. (1993). The Psychology of Attitudes. Fort Worth: Harcourt Brace

a. Jovanovich College Publishers.

8. Emerson, R., Fretz, R., \& Shaw, L., (1995). Writing ethnographic fieldnotes. Chicago: 


\section{INTERNATIONAL JOURNAL of RESEARCH -GRANTHAALAYAH \\ A knowledge Repository}

Science

a. University of Chicago Press.

9. Fox, N. J., \&. Ward, K. J. (2008). Pharma in the bedroom . . and the kitchen. . . The a. pharmaceuticalisation of daily life. Sociology of Health \& Illness 30 (6) 856-868

10. Gannon, K., Glover, L., \& Abel, P. (2004).Masculinity, infertility, stigma and media reports.

a. Social Science \& Medicine 59,1169-1175.

11. Greiling, H., \& Buss, D. M. (2000). Women's sexual strategies: Thehidden dimension of a. extra-pair mating. Personality and Individual Differences, 28, 929-963.

12. Hill, C. A., \& Preston, L. K. (1996). Individual differences in the experience of sexual a. motivation: Theory and measurement of dispositional sexual motives. Journal of Sex Research, 33, 27-45

13. Loe, M. (2004).The rise of viagra: How the little blue pill changed sex in America. New 14. York: New York University Press.

15. Rubin, R. (2004). Men talking about Viagra.Men and Masculinities. 7, (1), 22-30.

16. Sandroni, P. (2001). Aphrodisiacs past and present: A historical review. Clinical Autonomic

a. Response ,11, 303-307.

17. Schmitt, D. P. (2004). Patterns and universals of mate poaching across 53 nations: The effects

a. of sex, culture, and personality on romantically attracting another person. Journal of Personality and Social Psychology, 86, 560-584

18. Schmitt, D. P., \& Buss, D. M. (2001). Human mate poaching: Tacticsand temptations for

a. infiltrating existing relationships. Journal of Personality and Social Psychology, 80, 894-917.

19. Shamloul, R. (2010). Natural aphrodisiacs.Journal Sexual Medicine 7, 39-49.

20. Singh, B., Gupta, V., Bansal, P., Singh, R., \& Kumar, D. (2010). Pharmacological potential

21. of plant used as aphrodisiacs. International Journal of Pharmaceutical Sciences Review \& Research, 5(1), 104-113. 